\title{
Regulators of G-Protein Signaling (RGS) Proteins: Region-Specific Expression of Nine Subtypes in Rat Brain
}

\author{
Stephen J. Gold,, ${ }^{1,2}$ Yan G. Ni, ${ }^{1,2}$ Henrik G. DohIman, ${ }^{3}$ and Eric J. Nestler ${ }^{1,2,3}$ \\ ${ }^{1}$ Laboratory of Molecular Psychiatry and Departments of ${ }^{2}$ Psychiatry and ${ }^{3}$ Pharmacology, Yale University School of \\ Medicine, New Haven, Connecticut 06508
}

\begin{abstract}
The recently discovered regulators of G-protein signaling (RGS) proteins potently modulate the functioning of heterotrimeric G-proteins by stimulating the GTPase activity of G-protein $\alpha$ subunits. The mRNAs for numerous subtypes of putative RGS proteins have been identified in mammalian tissues, but little is known about their expression in brain. We performed a systematic survey of the localization of mRNAs encoding nine of these RGSs, RGS3-RGS11, in brain by in situ hybridization. Striking region-specific patterns of expression were observed. Five subtypes, RGS4, RGS7, RGS8, RGS9, and RGS10 mRNAs, are densely expressed in brain, whereas the other subtypes (RGS3, RGS5, RGS6, and RGS11) are expressed at lower density and in more restricted regions. RGS4 mRNA is notable for its dense expression in neocortex, piriform cortex, caudoputamen, and ventrobasal thalamus. RGS8 mRNA is highly expressed in the cerebellar Purkinje cell layer as well as in several midbrain nuclei. RGS9 mRNA is remarkable for its nearly exclusive en-
\end{abstract}

richment in striatal regions. RGS10 mRNA is densely expressed in dentate gyrus granule cells, superficial layers of neocortex, and dorsal raphe. To assess whether the expression of RGS mRNAs can be regulated, we examined the effect of an acute seizure on levels of RGS7, RGS8, and RGS10 mRNAs in hippocampus. Of the three subtypes, changes in RGS10 levels were most pronounced, decreasing by $\sim 40 \%$ in a timedependent manner in response to a single seizure. These results, which document highly specific patterns of RGS mRNA expression in brain and their ability to be regulated in a dynamic manner, support the view that RGS proteins may play an important role in determining the intensity and specificity of signaling pathways in brain as well as their adaptations to synaptic activity.

Key words: seizure; gene expression; striatum; neocortex; GTPase-activating proteins; Sst2; GAIP
The heterotrimeric G-proteins play a critical role in brain signal transduction by coupling extracellular receptors to intracellular signaling pathways. G-proteins are composed of single $\alpha, \beta$, and $\gamma$ subunits. The $\alpha$ subunits are guanine nucleotide-binding proteins that are regulated through cycles of GTP and GDP binding. In the inactive state, the $\alpha$ subunits are bound to GDP. They are activated by G-protein-coupled receptors (bound to ligand), which trigger the dissociation of GDP and the subsequent binding of GTP, which activates the $\alpha$ subunit. The active state is terminated when the intrinsic GTPase activity contained within the $\alpha$ subunit hydrolyzes GTP to GDP (for review, see Neer, 1995).

Recently, a newly discovered class of protein, termed regulators of G-protein signaling (RGS) proteins, has been shown to modulate the functioning of G-proteins by activating the intrinsic GTPase activity of the $\alpha$ subunits (for review, see Dohlman and Thorner, 1997; Koelle, 1997; Neer, 1997). RGS proteins thereby reduce the duration of the activated GTPbound state of the $\alpha$ subunit, which inhibits G-protein function. RGS proteins were first discovered in Saccharomyces cerevisiae, in which mutational analysis revealed a protein,

Received May 29, 1997; revised Aug. 1, 1997; accepted Aug. 5, 1997.

This work was supported by National Institutes of Health Grants DA08227 to E.J.N. and GM55316 to H.G.D. and by the Abraham Ribicoff Research Facilities of the Connecticut Mental Health Center, State of Connecticut Department of Mental Health and Addiction Services. We thank Dr. Michael Koelle for his generous gift of RGS cDNAs and for helpf ul discussions and Dr. Philip Iredale for striatal RNA.

Correspondence should be addressed to Eric J. Nestler, Department of Psychiatry, Yale University, 34 Park Street, New Haven, CT 06508.

Copyright (C) 1997 Society for Neuroscience $0270-6474 / 97 / 178024-14 \$ 05.00 / 0$
Sst2, with novel activity in inhibiting G-protein function (Chan and Otte, 1982; Dohlman et al., 1995). In the last two years, full or partial sequences of the mRNAs for numerous putative RGS proteins have been identified in diverse species (De Vries et al., 1995; Bruch and Medler, 1996; Chen et al., 1996, 1997; Druey et al., 1996; Koelle and Horvitz, 1996; Faurobert and Hurley, 1997). Eighteen RGS proteins have been identified to date in mammalian tissues; all are highly homologous within a so-called RGS domain. RGS proteins have recently been shown to function as GTPase-activating proteins for the Gi family of $\alpha$ subunit, including various isoforms of $\mathrm{G} \alpha \mathrm{i}, \mathrm{G} \alpha \mathrm{o}$, and transducin (G $\alpha \mathrm{t}$ ) (Berman et al., 1996a,b; Hunt et al., 1996; Watson et al., 1996; Hepler et al., 1997; Wieland et al., 1997). Some of the proteins also exhibit activity toward $\mathrm{G} \alpha \mathrm{q}$ but no detectable activity toward $\mathrm{G} \alpha \mathrm{s}$ or $\mathrm{G} \alpha 12$.

It is striking that the number of known RGS proteins exceeds the number of their target G-protein $\alpha$ subunits. This raises the question of how the specificity of RGS-dependent signaling is achieved. One possibility is that specificity results, at least in part, from different patterns of RGS expression. Indeed, Northern analysis revealed different tissue distributions of a small number of RGS proteins (De Vries et al., 1995; Chen et al., 1996, 1997; Druey et al., 1996; Koelle and Horvitz, 1996) with at least nine of the subtypes being present in brain (Koelle and Horvitz, 1996). We show here striking regional specificity of the expression of these RGS subtypes. We also show that the expression of several subtypes, RGS7, RGS8, and RGS10, is altered by acute seizure, which demonstrates the ability of the RGS proteins to be dynamically regulated in 
the nervous system. Together, these findings provide new leads to understand in much greater detail the mechanisms of brain signaling pathways and how the required intensity and specificity of signaling may be achieved.

\section{MATERIALS AND METHODS}

Animal treatments. Adult male Sprague Dawley rats (250-300 gm; Camm Research Institute, Wayne, NJ) were used for (1) histochemical localization $(n=3)$, (2) relative regional abundance analysis by Northern blot $(n=2)$, or (3) studies of electroconvulsive seizure (ECS; $n=20)$. ECS was administered as described previously (Winston et al., 1990). Briefly, electroconvulsive current $(40 \mathrm{~mA}, 0.3 \mathrm{sec})$ was administered via bilateral ear clips, and rats were killed $8 \mathrm{hr}(n=5), 24 \mathrm{hr}(n=5)$, or $7 \mathrm{~d}(n=5)$ later by perfusion; control rats $(n=5)$ were killed $24 \mathrm{hr}$ after ear clipping. After lethal sodium pentobarbital injections, rats were perfused transcardially with $50 \mathrm{ml}$ of saline in $0.1 \mathrm{M}$ sodium phosphate buffer $(\mathrm{PB})$ followed by $400 \mathrm{ml}$ of $4 \%$ paraformaldehyde in $0.1 \mathrm{M} \mathrm{PB}$ (PPB). Brains were removed from the skull, post-fixed in PPB for $24 \mathrm{hr}$, cryoprotected in $20 \%$ sucrose in PPB for $24 \mathrm{hr}$, and then sectioned into cold PPB with a freezing microtome, at $30 \mu \mathrm{m}$ in the coronal plane, from the nucleus accumbens through the midcerebellum ( 1 in 12 series, for localization studies) or from the fornix to temporal hippocampus (one in six series, for ECS studies). The olfactory bulb was cut parasaggitally (one in six series). Alternate tissue sections were then hybridized to the nine RGS cRNAs for localization studies or to RGS7, RGS8, or RGS10 cRNAs for the ECS studies.

In situ hybridization. Pretreatment and hybridization were that of Gall et al. (1995). Briefly, sections were permeabilized with proteinase K (1 $\left.\mu \mathrm{g} / \mathrm{ml}, 37^{\circ} \mathrm{C}, 30 \mathrm{~min}\right)$, treated with acetic anhydride containing triethanolamine $(0.1 \mathrm{M})$, washed in $2 \times \mathrm{SSC}(1 \times \mathrm{SSC}=0.15 \mathrm{M} \mathrm{NaCl}$ and 0.015 $\mathrm{M}$ sodium citrate, $\mathrm{pH}$ 7.0), and then hybridized free-floating for $24-36 \mathrm{hr}$ at $60^{\circ} \mathrm{C}$ in buffer containing formamide $(50 \%)$, polyvinyl pyrrolidone $(0.7 \%)$, Ficoll $(0.7 \%)$, bovine serum albumin $(7 \mathrm{mg} / \mathrm{ml})$, denatured salmon sperm DNA $(0.33 \mathrm{mg} / \mathrm{ml})$, yeast tRNA $(0.15 \mathrm{mg} / \mathrm{ml})$, dithiothreitol $(40 \mu \mathrm{M})$, and cRNA probe at $1 \times 10^{7} \mathrm{cpm} / \mathrm{ml}$. Sections were then rinsed in $4 \times \mathrm{SSC}\left(\mathrm{twice}, 60^{\circ} \mathrm{C}\right)$, treated with RNase A $(20 \mu \mathrm{g} / \mathrm{ml}, 30 \mathrm{~min}$ at $45^{\circ} \mathrm{C}$ ), washed in descending concentrations of SSC to a stringency of $0.1 \times \mathrm{SSC}$ at $37^{\circ} \mathrm{C}$, mounted onto gelatin-coated microscope slides, and air-dried. Tissue sections were exposed to $\beta$-max Hyperfilm (Amersham, Arlington Heights, IL) for 4-7 d. After film autoradiography, tissue sections were defatted in Americlear clearing reagent (VWR/Baxter, South Plainfield, NJ), dipped in NTB2 emulsion (Eastman Kodak, Rochester, NY), exposed for 2-5 weeks at $4^{\circ} \mathrm{C}$, developed with D19 (Kodak), fixed (Regular Fix, Kodak), counterstained with cresyl violet, and coverslipped with Permount.

Riboprobes. Antisense riboprobes were transcribed with T3 RNA polymerase (Stratagene, La Jolla, CA) in the presence of ${ }^{35}$ S-UTP (in situ hybridization) or ${ }^{32} \mathrm{P}-\mathrm{CTP}$ (Northern blot) (Dupont NEN, Boston, MA) and for in situ hybridization, phenol-chloroform-extracted and precipitated twice on dry ice with $0.3 \mathrm{M}$ sodium acetate/ethanol. Riboprobes for Northern analysis were purified with Nuc Trap minicolumns (Stratagene). RGS templates were generated by HindIII (antisense) or Bam HI (sense) digestion of pMK167, pMK152, pMK184, pMK186, pMK164, pMK153, pMK162, pMK190, and pMK175 plasmids generously provided by Michael Koelle (Yale University) (Koelle and Horvitz, 1996). All nine constructs contained $\sim 240$ bases inserted at the modified EcoRV site of Bluescript SK (Stratagene). Each 240 base insert was composed of a 200 base core sequence (available via GenBank, accession numbers U32434, U32327, U32435, U32436, U32328, U32432, U32433, U32437, and U32438 for RGS3-RGS11, respectively) flanked by $\sim 20$ base $5^{\prime}$ and $3^{\prime}$ PCR primer sequences, which are available on request. The antisense riboprobe sequences were aligned (MacVector, Kodak) and determined to share $\leq 73 \%$ sequence identity. Furthermore, all had similar GTP/CTP and UTP contents. The cyclophilin riboprobe was transcribed with T7 RNA polymerase (Boehringer Mannheim, Indianapolis, IN) from a HindIII digest of pGM-cyclo in which the coding region of rat cyclophilin was inserted into the BamHI site of PGEM-3Z (Promega, Madison, WI). For in situ hybridization, the labeling specificity of the riboprobes was established using sense riboprobes of the respective RGS subtypes. No specific labeling was observed for any of the sense cRNAs.

Northern blot hybridization. Tissue samples were obtained by gross dissection in chilled phosphate buffer containing $0.32 \mathrm{M}$ sucrose, rapidly frozen on dry ice, and stored at $-80^{\circ} \mathrm{C}$. Samples were homogenized with

\begin{tabular}{|c|c|}
\hline $\begin{array}{l}\text { RGS } \\
\text { subtype }\end{array}$ & Regions and cell types where most enriched \\
\hline RGS3 & Principal thalamic relay nuclei and white matter \\
\hline RGS4 & $\begin{array}{l}\text { Cortex, thalamus, and striatum, but noticeably low in hip- } \\
\text { pocampus }\end{array}$ \\
\hline RGS5 & $\begin{array}{l}\text { Paraventricular and supraoptic nuclei of hypothalamus, } \\
\text { basomedial amygdala, and glia }\end{array}$ \\
\hline RGS6 & $\begin{array}{l}\text { Olfactory bulb, scattered striatal cells, medial habenula, } \\
\text { reticular thalamic, subthalamic, and pontine nuclei }\end{array}$ \\
\hline RGS7 & Widespread, relatively high in cerebellar granule cells \\
\hline RGS8 & $\begin{array}{l}\text { Widespread, extremely dense in cerebellar Purkinje cells; } \\
\text { relatively dense in basal ganglia-related brainstem nuclei }\end{array}$ \\
\hline RGS9 & $\begin{array}{l}\text { Extremely dense in caudoputamen, nucleus accumbens, } \\
\text { and olfactory tubercle; relatively dense in medial hypo- } \\
\text { thalamus }\end{array}$ \\
\hline RGS10 & $\begin{array}{l}\text { Extremely dense in dentate gyrus granule cells; relatively } \\
\text { dense in superficial layers of neocortex and dorsal raphe }\end{array}$ \\
\hline RGS11 & Subfornical organ and locus coeruleus \\
\hline
\end{tabular}

a Brinkmann homogenizer in $4 \mathrm{~m}$ guanidium thiocyanate and $25 \mathrm{~mm}$ sodium acetate buffer containing $0.5 \%$ 2-mercaptoethanol, pelleted by centrif ugation through a $5.7 \mathrm{M}$ cesium chloride gradient at $150,000 \times \mathrm{g}$ at $20^{\circ} \mathrm{C}$ for $18 \mathrm{hr}$, resuspended in $0.3 \mathrm{~m}$ sodium acetate, $\mathrm{pH} \mathrm{5.2,} \mathrm{and}$ ethanol-precipitated. After the determination of RNA concentration by spectrophotometry, $10 \mu \mathrm{g}$ of RNA was electrophoresed along with RNA standards (0.24-9.5 kb; Life Technologies, Gaithersburg, MD) through a formaldehyde $/ 1.2 \%$ agarose gel containing ethidium bromide, transferred to nitrocellulose membranes (supported nitrocellulose-1, Life Technologies) by capillary blotting, and UV cross-linked to the membrane (Stratalinker, Stratagene). Northern blots were hybridized as described previously (Alvaro et al., 1996) for $18 \mathrm{hr}$ at $65^{\circ} \mathrm{C}$ in a roller tube oven in buffer containing $20 \mathrm{~mm}$ Tris- $\mathrm{HCl}, \mathrm{pH} \mathrm{7.5,0.1 \%}$ sodium pyrophosphate, $0.1 \%$ SDS, $0.2 \%$ polyvinyl pyrrolidone, $0.2 \%$ Ficoll, $5 \mathrm{~mm}$ EDTA, $10 \%$ dextran sulfate, $4 \times$ SSC, $50 \%$ deionized formamide, 100 $\mu \mathrm{g} / \mathrm{ml}$ denatured salmon sperm DNA and $2 \times 10^{6} \mathrm{cpm} / \mathrm{ml}$ (RGS) or $2 \times$ $10^{5} \mathrm{cpm} / \mathrm{ml}$ (cyclophilin) ${ }^{32} \mathrm{P}$-labeled riboprobes. Blots were washed to a stringency of $0.1 \times \mathrm{SSC} / 0.1 \%$ SDS at $65^{\circ} \mathrm{C}$, exposed to Hyperfilm MP (Amersham) for $3 \mathrm{~d}$ (RGS) or $1 \mathrm{~d}$ (cyclophilin), and developed with an X-OMAT film processor (Kodak). Blots were first probed with RGS cRNAs and 1 month later with cyclophilin cRNA.

Densitometry. Labeling densities of RGS7, RGS8, and RGS10 cRNA were determined by densitometry of autoradiographic film using National Institutes of Health Image analysis software, a Macintosh IIfx computer, and Northern Light illumination (Imaging Research, St. Catherine's, Ontario, Canada). Briefly, polynomial calibration curves were fitted to relative optical density values measured from known ${ }^{14} \mathrm{C}$-labeled radioactive standards (Amersham), which were coexposed to the film with tissue sections and related nanocuries per gram of tissue to relative optical density. Mean regional labeling densities for the dentate gyrus granule cell layer and parietal cortex were taken from at least two brain sections per animal (both hemispheres) and are expressed as nanocuries per gram of tissue. With modifications, abbreviations are those of Paxinos and Watson (1986).

\section{RESULTS}

\section{Overview}

The labeling patterns produced by the nine RGS cRNAs were highly specific for each RGS subtype. The specificity of hybridization was achieved by the use of high stringency conditions and was verified by hybridization of sense cRNAs for each transcript. General features of subtype cRNA labeling patterns are described in this section and in Table 1. A more detailed analysis of the regional and cellular hybridization patterns will be described in the following section and is summarized in Table 2. Finally, 
Table 2. Regional labeling densities for RGS cRNA probes

\begin{tabular}{|c|c|c|c|c|c|c|c|c|c|}
\hline & RGS3 & RGS4 & RGS5 & RGS6 & RGS7 & RGS8 & RGS9 & RGS10 & RGS11 \\
\hline \multicolumn{10}{|l|}{ Telencephalon } \\
\hline \multicolumn{10}{|l|}{ Neocortex } \\
\hline Layer I & 0 & 0 & + & 0 & 0 & 0 & 0 & + & 0 \\
\hline Layer II & 0 & +++++ & + & + & +++ & +++ & 0 & +++++ & 0 \\
\hline Layer III & 0 & +++++ & + & + & +++ & 0 & 0 & +++++ & 0 \\
\hline Layer IV & 0 & + & + & + & + & 0 & 0 & + & 0 \\
\hline Layer V & 0 & +++++ & + & + & + & 0 & 0 & + & 0 \\
\hline Layer VI & 0 & ++ & + & + & + & + & + & + & 0 \\
\hline Piriform cortex & + & +++++ & + & + & +++++ & + & + & +++ & 0 \\
\hline Nucleus accumbens & 0 & +++ & + & 0 & + & ++++ & +++++ & + & 0 \\
\hline Caudoputamen & 0 & +++ & + & 0 & + & +++ & +++++ & ++ & 0 \\
\hline Olfactory tubercle & 0 & +++ & + & 0 & + & ++++ & +++++ & + & 0 \\
\hline Lateral septum & 0 & 0 & + & + & + & 0 & 0 & ++ & 0 \\
\hline Medial septum & 0 & +++ & + & 0 & + & +++ & 0 & + & 0 \\
\hline \multicolumn{10}{|l|}{ Hippocampus } \\
\hline Stratum pyramidale & 0 & + & + & 0 & +++ & +++ & 0 & + & + \\
\hline Stratum granulosum & 0 & + & + & 0 & +++ & + & + & +++++ & + \\
\hline Molecular layers & 0 & 0 & + & 0 & 0 & + & 0 & + & 0 \\
\hline \multicolumn{10}{|l|}{ Amygdala } \\
\hline bst & 0 & +++++ & 0 & 0 & + & + & + & 0 & 0 \\
\hline Central amygdala & 0 & +++++ & + & 0 & + & + & + & + & 0 \\
\hline Lateral amygdala & 0 & +++++ & + & 0 & +++ & + & 0 & + & 0 \\
\hline Basolateral amygdala & 0 & ++++ & +++++ & 0 & +++ & + & 0 & + & 0 \\
\hline Medial amygdala & 0 & ++ & + & 0 & +++ & + & ++ & + & 0 \\
\hline \multicolumn{10}{|l|}{ Diencephalon } \\
\hline Medial habenula & 0 & + & + & +++++ & + & +++++ & + & 0 & 0 \\
\hline Lateral habenula & 0 & 0 & + & 0 & + & +++ & 0 & + & 0 \\
\hline \multicolumn{10}{|l|}{ Thalamus } \\
\hline Principal relay nuc & ++++ & +++++ & + & $+++^{a}$ & +++ & ++++ & 0 & 0 & 0 \\
\hline Midline/intralaminar nuc & +++ & +++++ & + & 0 & +++ & +++++ & 0 & + & 0 \\
\hline Reticular nuc & 0 & 0 & + & ++++ & + & 0 & 0 & 0 & 0 \\
\hline Subthalamic nuc & 0 & +++ & + & +++++ & ++++ & ++++ & 0 & + & 0 \\
\hline \multicolumn{10}{|l|}{ Hypothalamus } \\
\hline Paraventricular nuc & 0 & +++++ & +++++ & 0 & ++ & 0 & ++ & 0 & 0 \\
\hline Supraoptic nuc & 0 & +++++ & +++++ & 0 & +++ & + & +++ & 0 & 0 \\
\hline Suprachiasmatic nuc & 0 & ++ & + & 0 & + & ++ & +++ & +++ & 0 \\
\hline Ventromedial nuc & 0 & + & + & 0 & +++ & + & +++ & 0 & 0 \\
\hline Arcuate nuc & 0 & + & + & 0 & ++ & + & ++++ & 0 & 0 \\
\hline Medial mammillary nuc & ++ & +++++ & + & ++++ & +++++ & ++++ & 0 & + & 0 \\
\hline Lateral mammillary nuc & 0 & +++++ & + & 0 & ++ & 0 & 0 & ++ & 0 \\
\hline \multicolumn{10}{|l|}{ Brainstem } \\
\hline Substantia nigra (pc) & + & + & + & ++ & ++ & ++++ & 0 & 0 & 0 \\
\hline Ventral tegmental area & + & + & + & ++ & ++ & +++++ & 0 & 0 & 0 \\
\hline Central gray & 0 & +++ & + & 0 & +++ & +++++ & 0 & ++ & 0 \\
\hline Superior colliculus & 0 & + & + & + & +++ & ++++ & 0 & +++ & 0 \\
\hline Inferior colliculus & + & + & + & 0 & +++ & +++ & 0 & +++++ & 0 \\
\hline Interpeduncular nuc & + & + & + & +++ & +++ & ++++ & 0 & + & 0 \\
\hline Pontine nuc & 0 & ++++ & +++ & +++++ & +++ & +++++ & 0 & +++ & + \\
\hline Dorsal raphe & 0 & 0 & + & + & ++ & ++++ & + & +++++ & + \\
\hline Locus coeruleus & +++ & +++++ & + & +++ & +++++ & +++++ & + & 0 & +++ \\
\hline \multicolumn{10}{|l|}{ Cerebellum } \\
\hline Purkinje cell layer & + & + & + & + & 0 & +++++ & 0 & + & 0 \\
\hline Granule cell layer & 0 & 0 & 0 & 0 & ++++ & + & 0 & + & 0 \\
\hline
\end{tabular}

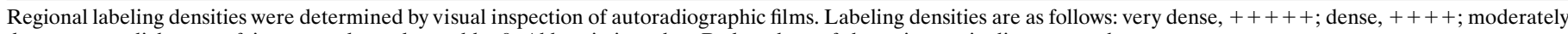
dense, +++ ; light, ++ ; faint, + ; and not detectable, 0 . Abbreviations: bst, Bed nucleus of the stria terminalis; nuc, nucleus; pc, pars compacta.

${ }^{a}$ Labeling restricted to subset of anterior thalamic nuclei. 

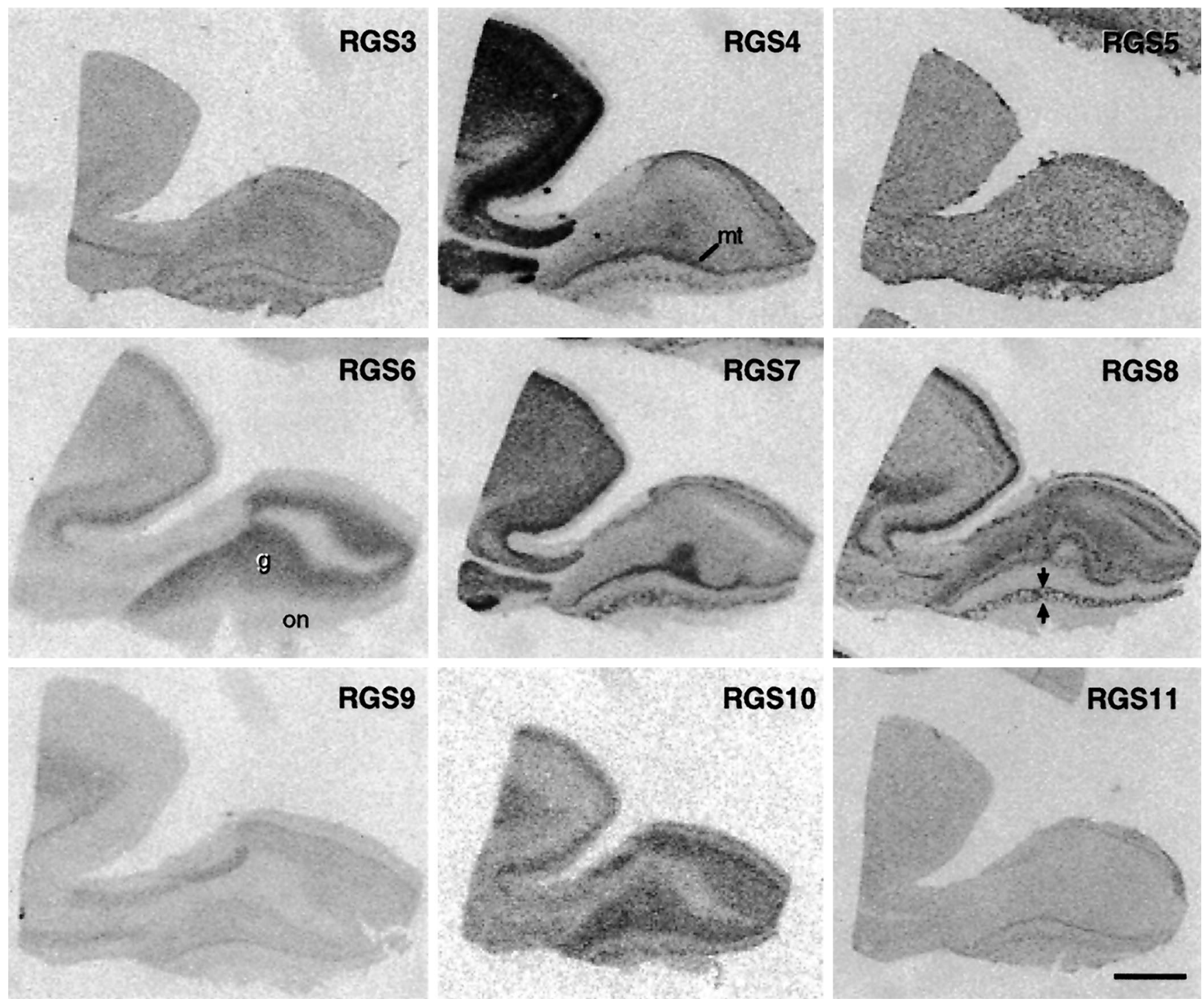

Figure 1. Bright-field photomicrographs of film autoradiograms of in situ hybridization to the nine RGS cRNAs through parasaggital sections of olfactory bulb. In this figure and in Figures 2-10, exposure times were identical for all nine probes. $m t$, Mitral, tufted cell layer; $g$, granule cell layer; on, olfactory nerve layer; opposing arrows, glomerular cell layer. Scale bar, $1.7 \mathrm{~mm}$.

regulation of the expression of RGS7, RGS8, and RGS10 mRNAs by acute ECS is presented.

Of the nine RGS subtypes surveyed, five of the cRNAs densely labeled brain. These included RGS4, RGS7, RGS8, RGS9, and RGS10 cRNAs. Although specific labeling in brain was also observed for the four other subtypes, labeling tended to be at a lower density and in more restricted sets of brain regions. Labeling by RGS3 cRNA was restricted to dorsal thalamus and white matter. RGS4 cRNA most densely labeled several layers of neocortex, piriform cortex, caudoputamen, and ventrobasal thalamus. RGS5 cRNA densely labeled only three neuronal populations, the paraventricular and supraoptic hypothalamic nuclei and parts of the basolateral amygdaloid complex. In addition, diff use labeling across all tissue sections and dense labeling in glia-enriched layers of hippocampus suggested glial expression of RGS5 mRNA. RGS6 cRNA most densely labeled the olfactory bulb granule cell layer, scattered cells in the caudoputamen, the reticular thalamic nucleus, the medial habenula, the subthalamic nucleus, and several other brainstem nuclei. Labeling by RGS7 cRNA was wide- spread. RGS8 cRNA labeling was extremely dense in the cerebellar Purkinje cell layer, with less dense yet still marked labeling occurring in numerous other regions. Labeling by RGS9 cRNA was remarkable for its nearly exclusive enrichment in striatum. RGS10 cRNA labeling was by far most enriched in the dentate gyrus granule cell layer. Finally, RGS11 cRNA labeling was restricted to the subfornical organ and the caudal locus coeruleus.

\section{Detailed analysis}

The cRNAs used for this analysis are identical in length, contain similar levels of GTP and CTP, and have comparable levels of ${ }^{35}$ S-UTP incorporation. Additionally, and unless noted, photomicrographs of cRNA labeling for the nine RGSs were taken from film autoradiograms of identical exposure times. Thus, the panels represent reasonable approximations of relative mRNA densities for the RGS subtypes. All estimations of relative labeling densities between RGS cRNAs were determined by visual inspection of the film autoradiograms. Importantly, for each cRNA, the 

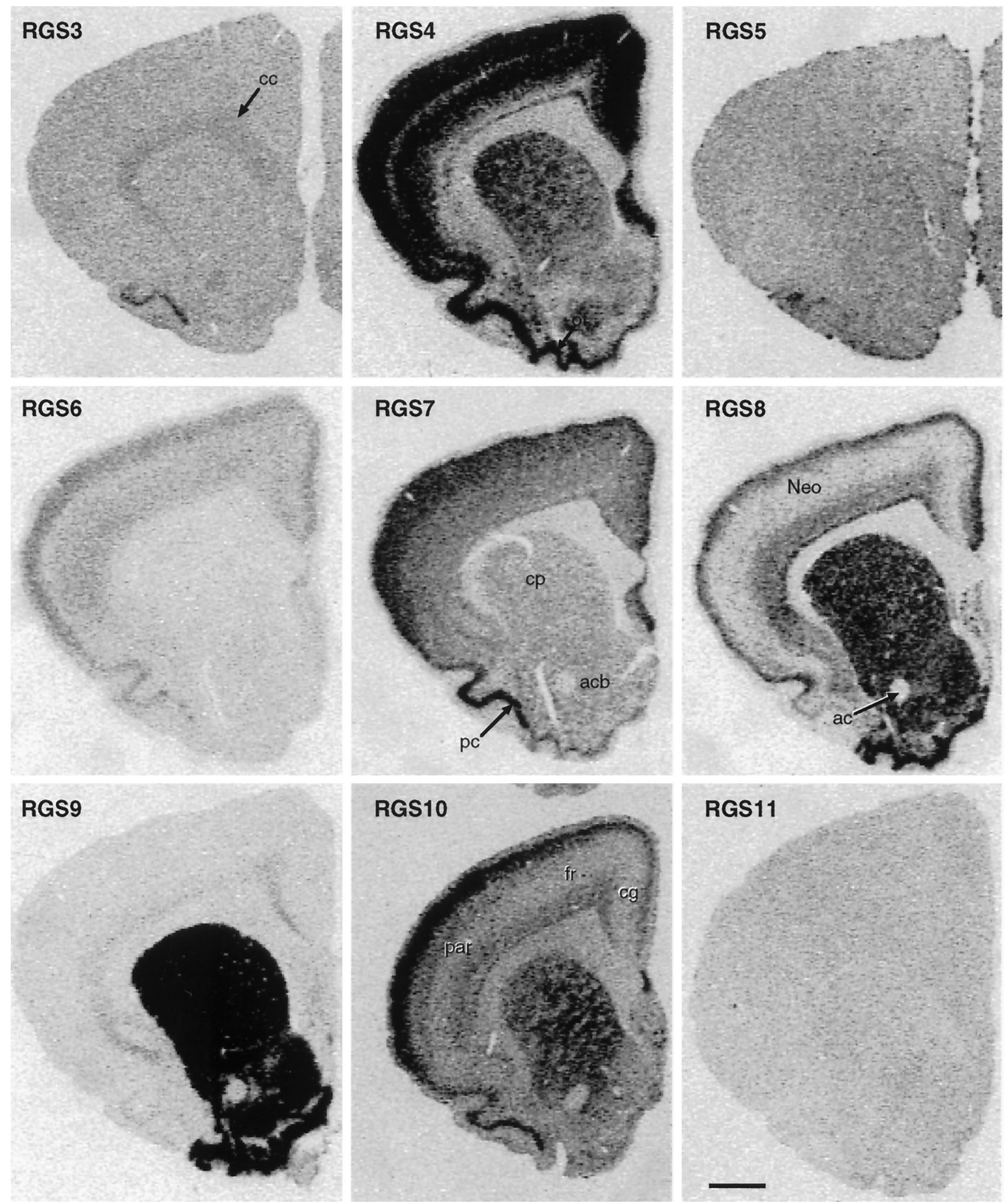

Figure 2. Bright-field photomicrographs of film autoradiograms illustrating the labeling patterns of RGS cRNAs through rostral striatum and nucleus accumbens. Note the striking enrichment of (1) RGS4 cRNA labeling in neocortex (Neo) and (2) RGS9 cRNA labeling in caudoputamen ( $c p$ ), accumbens $(a c b)$, and olfactory tubercle $(o t)$. Also note the lower RGS10 cRNA labeling densities in frontal $(f r)$ and cingulate $(c g)$ cortices relative to parietal cortex ( par). $c c$, Corpus callosum; $p c$, piriform cortex. Scale bar, $1.1 \mathrm{~mm}$. 

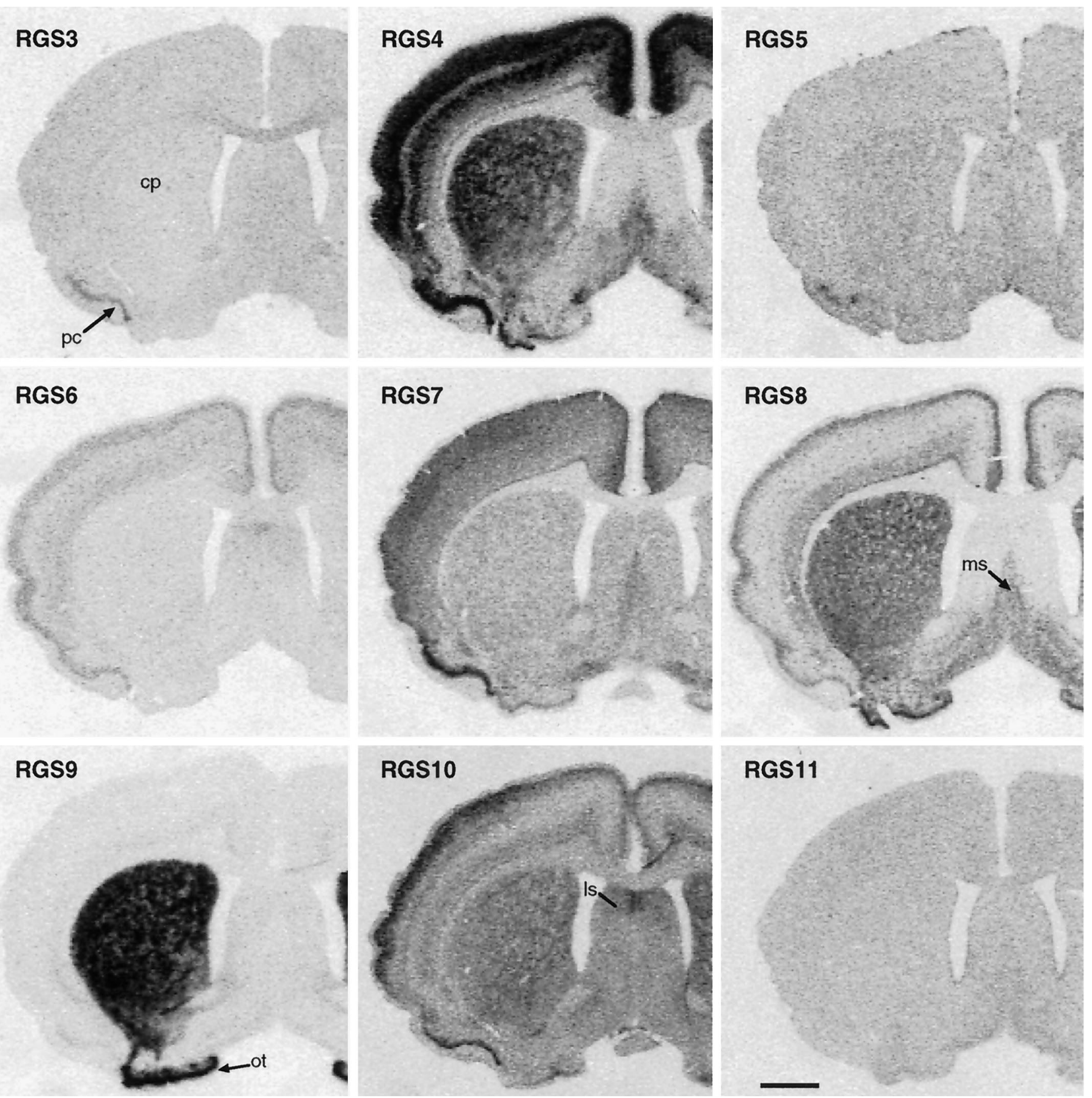

Figure 3. Bright-field photomicrographs of film autoradiograms showing the hybridization patterns of RGS3-RGS11 cRNAs. Note the overall paucity of labeling in lateral septum $(l s)$ and the relatively dense labeling of RGS4 and RGS8 cRNAs in medial septum ( $m s)$. $c p$, Caudoputamen; ot, olfactory tubercle. Scale bar, $1.4 \mathrm{~mm}$.

hybridization patterns were virtually indistinguishable between rats $(n=3)$ and independent hybridizations $(\geq 2)$.

\section{Telencephalon}

In olfactory bulb (Fig. 1), five of the RGS subtype mRNAs showed moderate to high levels of expression. Dense RGS4 cRNA labeling was restricted to the mitral, tufted cell layer. RGS6 and RGS10 cRNAs labeled the granule cell layer moderately densely. RGS7 and RGS8 mRNAs were expressed in several different layers of bulb. Both of these subtype cRNAs had mod- erate labeling densities in the glomerular cell layer. In the mitral, tufted cell layer, however, RGS7 cRNA labeling was dense, whereas RGS8 cRNA labeling was only moderately dense.

The principal features of neocortical labeling can be appreciated in Figures 2-4. Subtype cRNA labeling in neocortex was by far most dense for RGS4. Indeed it appeared that RGS4 cRNA labeling in cortex was denser than in any other brain region examined. Less yet considerable hybridization was present for RGS7 and RGS10 cRNAs. The laminar profile of subtype cRNA 

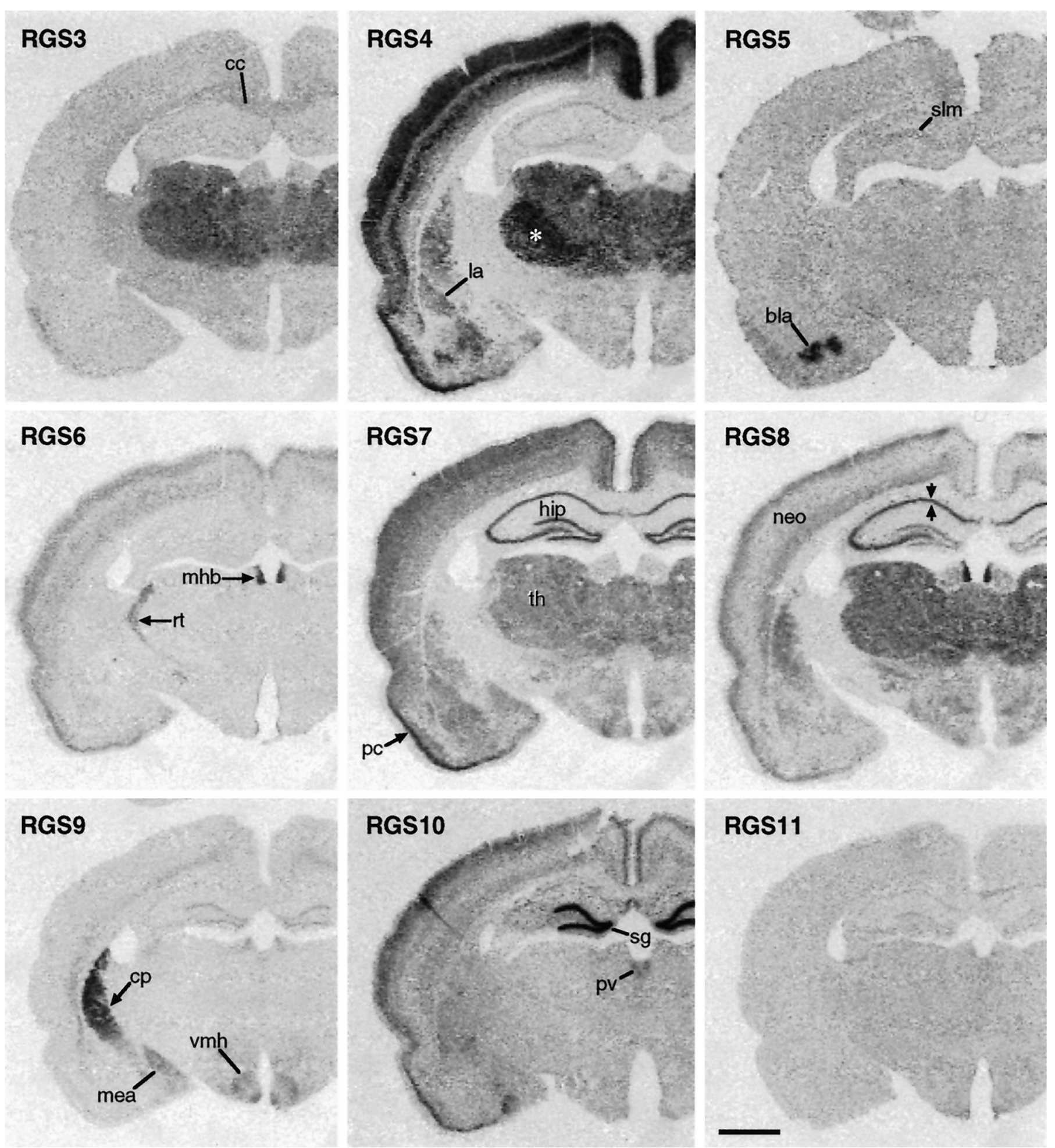

Figure 4. Bright-field photomicrographs of film autoradiograms of RGS cRNA labeling patterns in coronal planes of section through septal hippocampus (hip). bla, Basolateral amygdaloid nucleus; $c c$, corpus callosum; $c p$, caudoputamen; la, lateral amygdaloid nucleus; $m e a$, medial amygdaloid nucleus; $m h b$, medial habenula; $t h$, thalamus; $p v$, paraventricular thalamic nucleus; $s l m$, stratum lacunosum moleculare; $r t$, reticular thalamic nucleus; $v m h$, ventromedial hypothalamic nucleus; opposing arrows, hippocampal stratum pyramidale; asterisk, ventrobasal thalamus. Scale bar, $1.8 \mathrm{~mm}$.

labeling can be seen in Figures $2-5$ and is detailed more fully in Table 2. With the exception of RGS10 cRNA, all subtype cRNAs had similar laminar expression patterns between cortical areas. For RGS10, however, cRNA labeling was relatively less dense in superficial layers of frontal and cingulate/retrosplenial cortices.
Interestingly, in emulsion autoradiograms of RGS8 cRNA hybridization, densely labeled cells were diffusely distributed across neocortical layers, with no apparent relation to laminar boundaries (Fig. 5B).

In the rostral caudoputamen and nucleus accumbens, the most 

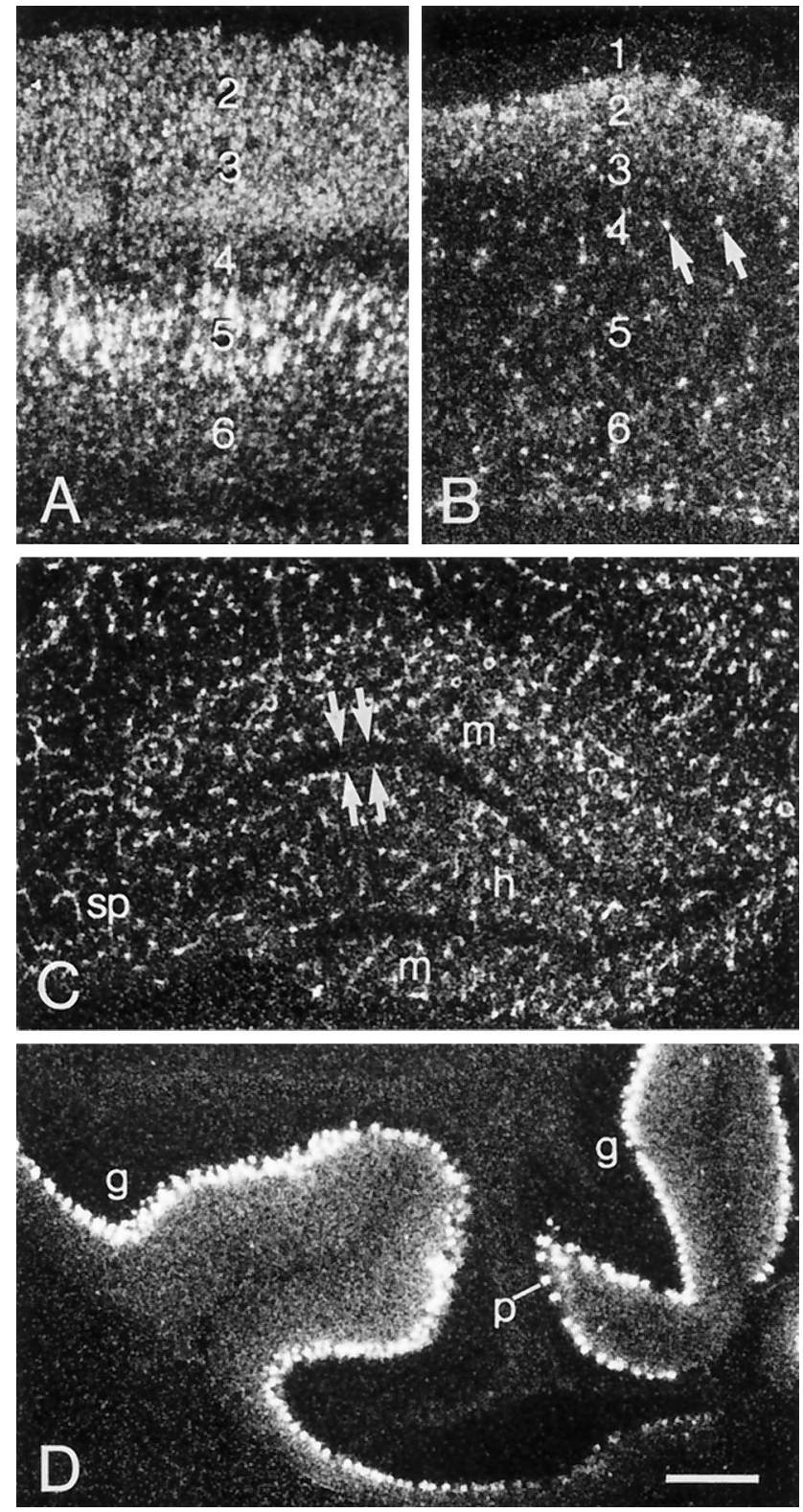

Figure 5. Dark-field photomicrographs of emulsion autoradiograms showing cRNA labeling patterns across laminae of neocortex $(A, B)$ dentate gyrus $(C)$ and cerebellar cortex $(D)$. Note that exposure times varied between subtype cRNAs and are not intended to depict relative labeling densities between RGS cRNAs. Representative labeling patterns for RGS4 cRNA $(A)$ and RGS8 cRNA $(B)$ are illustrated in crosssections of parietal neocortex and temporal neocortex, respectively. Layers are indicated by numbers with the exception of layer 1 in $A$ (unlabeled zone at top). Note the scattered cells (arrows) densely labeled by RGS8 cRNA. In $C$, fibrillar RGS5 cRNA labeling excludes both the dentate gyrus granule cell layer (opposing arrows) and CA3 stratum pyramidale $(s p)$ but is enriched in the dentate gyrus molecular layer $(\mathrm{m})$ and hilus $(h r)$. In $D$, the extremely dense RGS8 cRNA labeling of the cerebellar Purkinje cell layer $(P)$ is apparent. $g$, Cerebellar granule cell layer. Scale bar: $A, B, 260 \mu \mathrm{m} ; C, D, 290 \mu \mathrm{m}$.

striking feature was the extremely dense RGS9 cRNA labeling throughout the entire rostral and caudal extent of the structures (Figs. 2-4). Other subtypes with considerable cRNA labeling densities in these basal ganglia structures were RGS4, RGS8, and RGS10. In addition to the dense expression of these four subtype mRNAs, emulsion autoradiograms revealed that scattered cells throughout the caudoputamen were densely labeled by RGS6 cRNA (Fig. $6 A$ ). In lateral septum, the only RGS cRNAs showing appreciable labeling were those for RGS6 and RGS10. Even then, they labeled at only a moderate density (Figs. 3, 6A). In medial septum and the vertical limb of the diagonal band of Broca, RGS4 and RGS8 cRNAs labeled most densely.

In hippocampus, overall labeling was most dense for RGS7, RGS8, and RGS10 cRNAs. In the dentate gyrus granule cell layer, labeling by RGS10 cRNA was extremely dense, whereas that for RGS7 cRNA was substantially less dense (Fig. 4). In the pyramidal cell layers, RGS7 and RGS8 cRNA labeling predominated. Nevertheless, in temporal hippocampus, RGS4 cRNA labeled the pyramidal cell layer at a significant density (data not shown). In addition to labeling within the principal neuronal layers, cells labeled by RGS8 and RGS10 cRNAs were scattered across the hippocampal molecular layers. Finally, diff use RGS5 cRNA labeling was most enriched in CA1 stratum lacunosum moleculare (Figs. 4, 5C).

Across the amygdaloid complex, patterns of labeling were remarkably differentiated, and for RGS4 cRNA in particular, differed across subregions of specific nuclei. In the nucleus of the lateral olfactory tract, RGS4 and RGS8 cRNA labeling was most dense (data not shown). In the bed nucleus of the stria terminalis and the central amygdaloid nucleus, subtype cRNA labeling was most dense for RGS4 with less dense cRNA labeling for RGS7, RGS8, and RGS9 (Fig. 6B). The lateral and basolateral amygdaloid nuclei were also densely labeled by RGS4 cRNA (subregions; Figs. 4, 6B). Minor contributions to the hybridization signal came from the RGS7 cRNA. In the basomedial and basoventral subnuclei of the basolateral nucleus, however, RGS5 cRNA labeling was clearly predominant (Fig. 4). In the medial amygdaloid nuclei, total cRNA labeling densities were relatively lower, with the predominant subtypes being RGS4, RGS7, and RGS9 (Fig. 4).

\section{Diencephalon}

In the majority of dorsal thalamus, labeling was dominated by RGS3, RGS4, RGS7, and RGS8 cRNAs (Fig. 4). At least two notable exceptions to this pattern were observed. In the anterior thalamic nuclei there was a conspicuous absence of labeling by RGS4 cRNA and a notable presence of labeling by RGS6 cRNA (Fig. 6B). The balance of labeling in the ventrobasal complex also deviated from the prototypical thalamic pattern, with particularly dense labeling by RGS4 cRNA (Fig. 4).

Outside of dorsal thalamus, the balance of cRNA labeling differed in at least five ways. First, hybridization to RGS3 cRNA did not extend beyond dorsal thalamus. Second, within the lateral parafascicular thalamic nucleus, RGS8 was by far the most densely labeling subtype cRNA (Fig. 7). Third, in the reticular thalamic nucleus, subtype cRNA labeling was dominated by RGS6 (Fig. 4). Fourth, in medial habenula, labeling densities were highest for RGS8 cRNA and slightly less for RGS6 cRNA (Figs. 4, 7). Finally, in the subthalamic nucleus, labeling was most dense for RGS6 cRNA with just less dense labeling by RGS7 and RGS8 cRNAs (Fig. 7). As in many other regions, dense RGS4 cRNA labeling in the subthalamic nucleus was restricted to a subregion.

Although most hypothalamic nuclei appeared to be labeled by one or more of the RGS cRNAs, a complete description of labeling patterns within hypothalamus is beyond the scope of this paper. Nevertheless, hypothalamic labeling highlights will be described briefly. Throughout hypothalamus, RGS7 and RGS8 cRNA labeling were most ubiquitous. In addition, RGS9 cRNA 

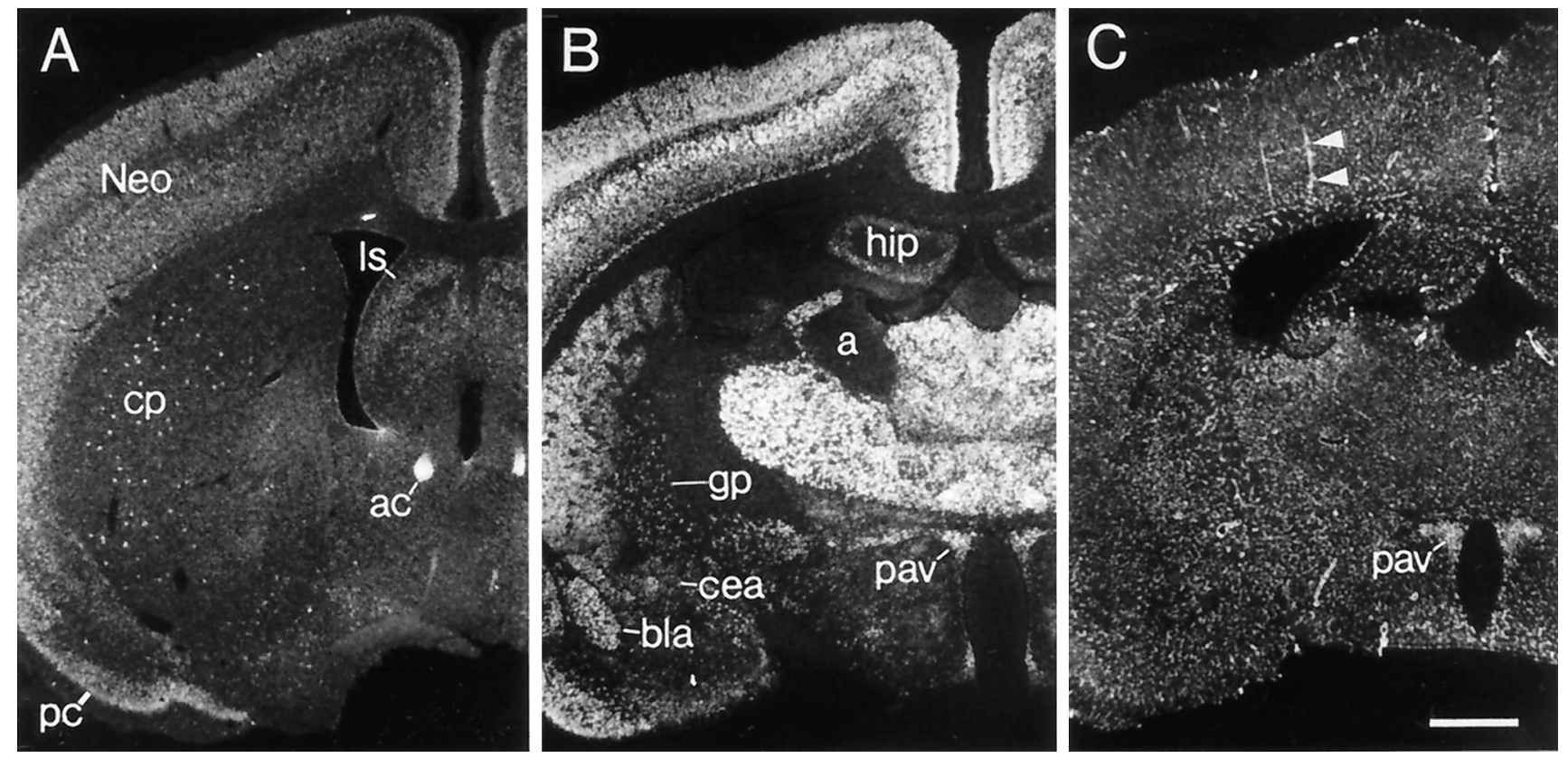

Figure 6. Dark-field photomicrographs of emulsion autoradiograms illustrating subtle features of RGS6, RGS4, and RGS5 cRNA labeling. Note that subtype exposure times varied and hence do not reflect relative labeling densities between RGS cRNAs. $A$, Dense RGS6 cRNA labeling of scattered cells in caudoputamen $(c p)$ and of the anterior commissural nucleus $(a c)$. Less dense labeling occurred in neocortex (Neo), lateral septum $(l s)$, and piriform cortex $(p c) . B, C$, Dense labeling by RGS4 and RGS5 cRNAs in paraventricular hypothalamic nucleus ( pav). Note also the relatively low levels and complete absence of RGS4 cRNA labeling in hippocampus (hip) and anterior thalamus (a), respectively. Finally, note the fibrillar appearance of RGS5 cRNA labeling throughout the tissue section and dense labeling of the vasculature (arrowheads). cea, Central amygdaloid nucleus; gp, globus pallidus; bla, basolateral amygdaloid nucleus. Scale bar, $1.2 \mathrm{~mm}$.

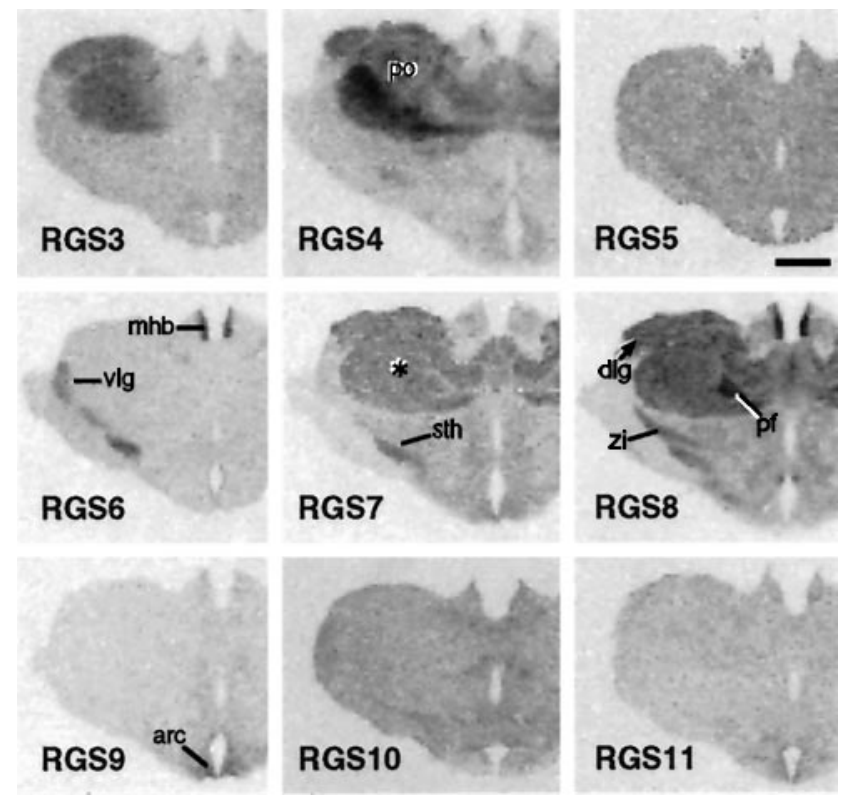

Figure 7. Bright-field photomicrographs of film autoradiograms of in situ hybridization to the nine RGS cRNAs in coronal sections through caudal diencephalon. arc, Arcuate nucleus; $d l g$, dorsolateral geniculate nucleus; $m h b$, medial habenula; $p f$, lateral parafascicular thalamic nucleus; $p o$, posterior thalamic nucleus; sth, subthalamic nucleus; vlg, ventrolatera geniculate nucleus; $z i$, zona incerta; asterisk, ventrobasal thalamus; Scale bar, $1.4 \mathrm{~mm}$.

tended to label numerous medial hypothalamic nuclei at a moderate to high density.

The supraoptic and paraventricular nuclei had similar cRNA labeling patterns; RGS4 and RGS5 cRNAs labeled densely (Fig.
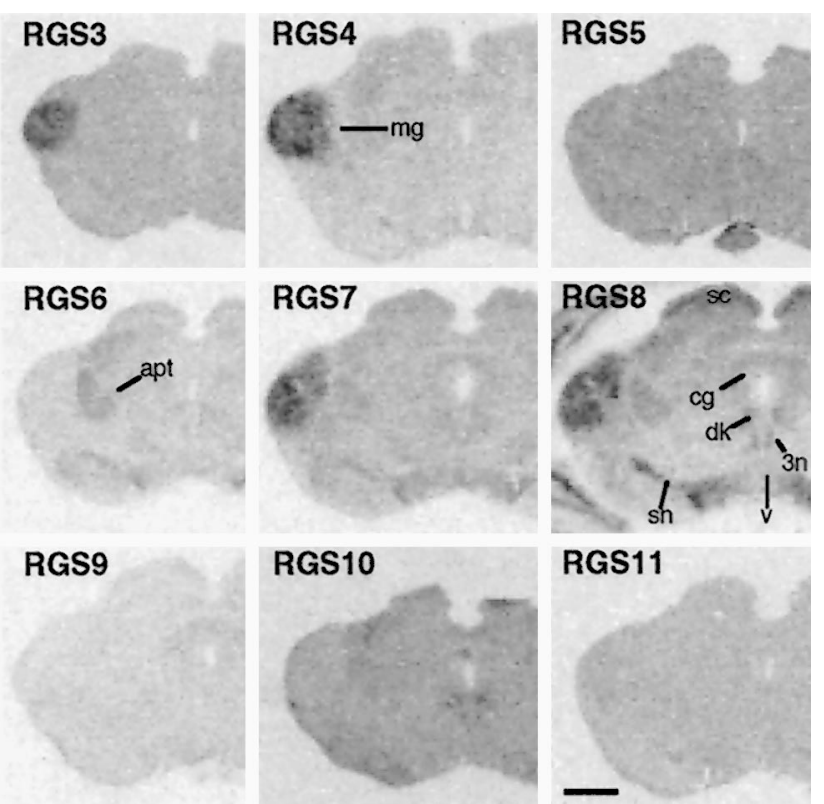

Figure 8. Bright-field photomicrographs of film autoradiograms illustrating RGS cRNA labeling in coronal sections through the mesodiencephalic border. $3 n$, Oculomtor nucleus; apt, anterior pretectal nuclei; $c g$, central gray; $d k$, nucleus darkewisch; $m g$, medial geniculate nucleus; $s c$, superior colliculus; sn, substantia nigra pars compacta; $v$, ventral tegmental area. Scale bar, $1.2 \mathrm{~mm}$.

$6 B, C)$, whereas RGS7 and RGS9 cRNAs were minor contributors. The suprachiasmatic nucleus exhibited a different pattern; RGS9 and RGS10 cRNAs labeled at the highest density, with slightly lower labeling densities for RGS4 and RGS8 cRNAs. Yet 

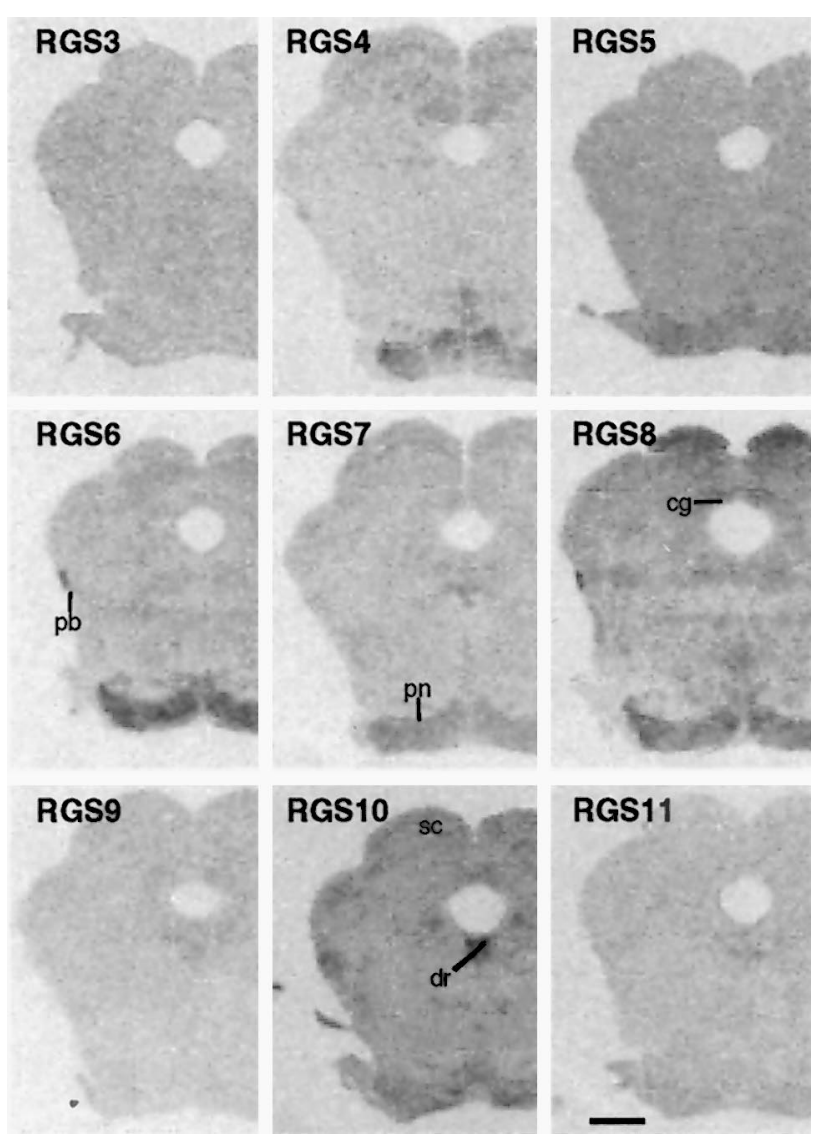

Figure 9. Bright-field photomicrographs of film autoradiograms showing in situ hybridization of RGS cRNAs in coronal sections through superior colliculus $(s c)$ and pontine nuclei $(p n) . c g$, Central gray; $d r$, dorsal raphe; $p b$, parabigeminal nucleus. Scale bar, $1.0 \mathrm{~mm}$.

a third pattern emerged for the ventromedial and arcuate nuclei; moderately dense labeling by RGS7 and RGS9 cRNAs was predominant, with lighter labeling by RGS4 and RGS8 cRNAs (Figs. 4, 7).

\section{Mesencephalon and caudal brainstem}

As with hypothalamus, descriptions of RGS cRNA labeling will be limited to several major mesencephalic and metencephalic structures. As can be seen in Figure 8, labeling in the substantia nigra pars compacta and ventral tegmental area was dominated by RGS8 cRNA. In central gray, labeling for RGS7 and RGS8 cRNAs was predominant. (Figs. 8, 9) Moderate labeling by RGS4 cRNA was present in the dorsal aspect of the central gray. The inferior and superior colliculi shared similar cRNA labeling patterns such that in both regions RGS8 and RGS10 cRNAs labeled most densely, with slightly lower levels for RGS7 cRNA (Figs. 9, 10). Finally, in the pontine nuclei, total cRNA labeling was very dense. The RGS6 cRNA labeled most densely. Slightly less dense labeling occurred for RGS5, RGS7, RGS8, and RGS10 cRNAs (Figs. 9, 10). Similar to numerous other brain regions, RGS4 cRNA labeling densities were heterogeneous across the pontine nuclei.

In cerebellar cortex, the most striking feature was the extremely dense labeling of the Purkinje cell layer by RGS8 cRNA (Figs. 5D, 11). A more modest signal was observed there for RGS10 cRNA. Almost as striking as cerebellar RGS8 cRNA

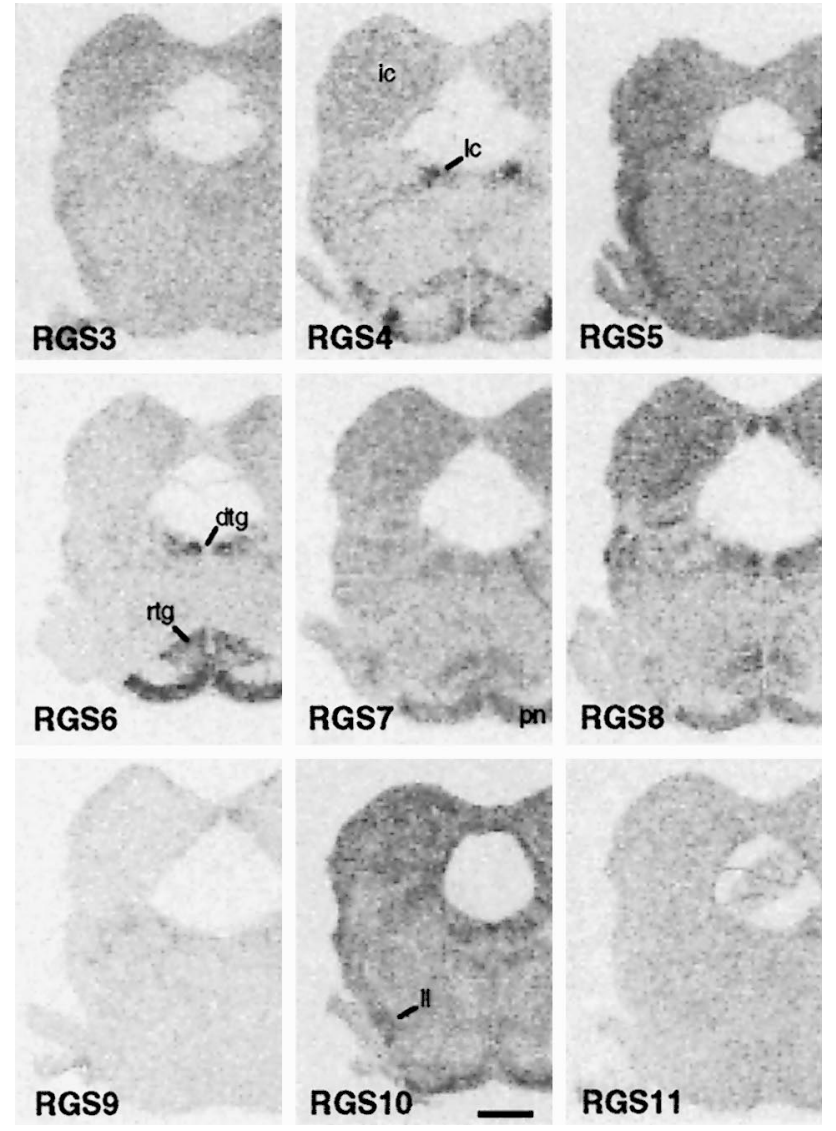

Figure 10. Bright-field photomicrographs of film autradiograms of in situ hybridization of RGS cRNAs in coronal sections through the inferior colliculus (ic) and pontine nuclei. $d t g$, Dorsal tegmental nucleus; $l c$, locus coeruleus; rtg, reticulotegmental nucleus; $l l$, nucleus of the lateral lemniscus. Scale bar, $1.0 \mathrm{~mm}$.

labeling was the moderately dense RGS7 cRNA labeling of the granule cell layer.

Labeling in the dorsal raphe was dominated by RGS10 cRNA (Fig. 9). In locus coeruleus, labeling was dominated by RGS4 and RGS7 cRNAs, with a lesser yet considerable presence of RGS3, RGS8, and RGS11 cRNA labeling (Fig. 11).

\section{Northern blot analysis}

To substantiate the findings from in situ hybridization, four of the nine RGS cRNAs were used to screen Northern blots of neocortical, hippocampal, striatal, and cerebellar RNA. Relative hybridization densities across the four brain regions were in good agreement with that found using in situ hybridization and served as an additional confirmation of the hybridization specificity of these cRNAs. Thus, the hybridization signal was greatest in (1) neocortex for RGS4, (2) cerebellum for RGS8, (3) striatum for RGS9, and (4) hippocampus and striatum for RGS10. Furthermore, RGS4, RGS8, RGS9, and RGS10 cRNAs hybridized to principal bands of unique sizes corresponding to 3.4, 6.6, 2.6, and $1 \mathrm{~kb}$ transcript lengths, respectively (Fig. 12). Minor hybridization bands were also observed for RGS9 and RGS8.

\section{Regulation of RGS10 and other subtypes by seizure}

In several eukaryotic systems, RGS activity is regulated at the level of expression (for review, see Dohlman and Thorner, 1997). 

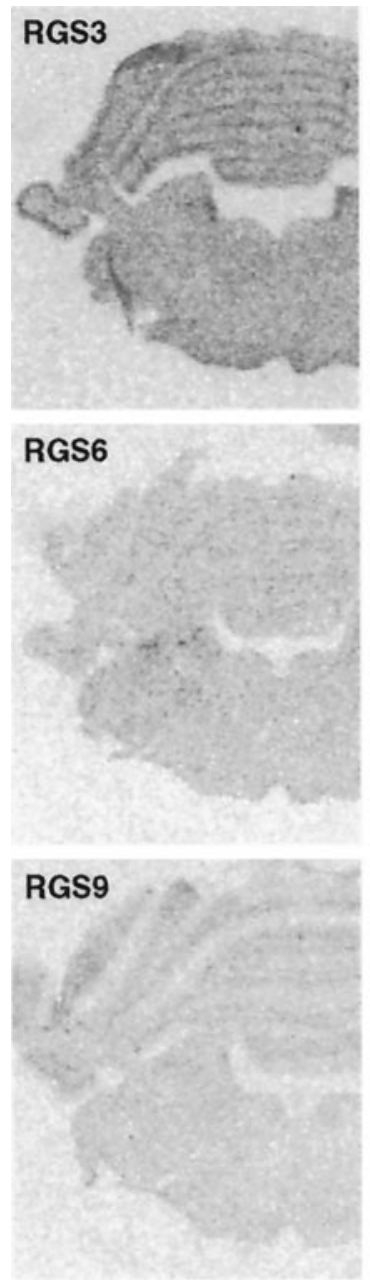
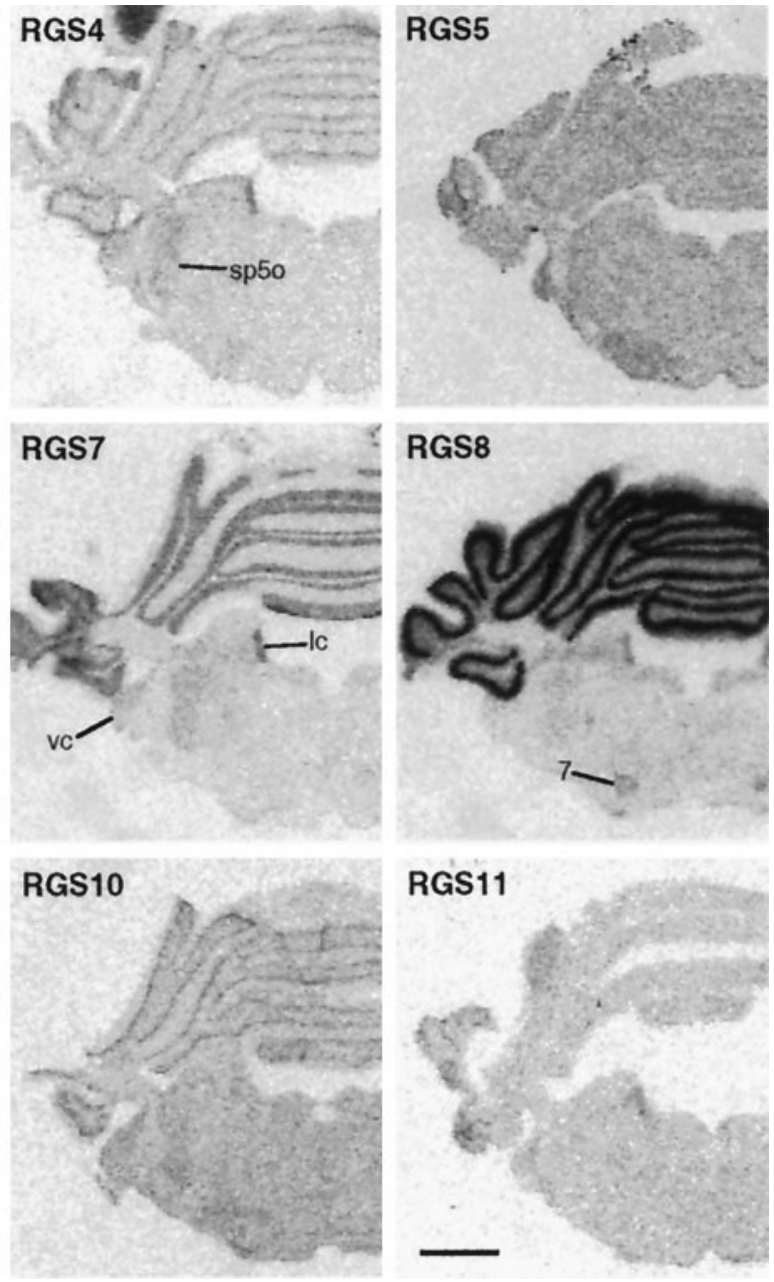

Figure 11. Bright-field photomicrographs of film autoradiograms of RGS cRNA labeling in coronal planes through cerebellum at the level of the caudal locus coeruleus. $l c$, Locus coeruleus; $s p 5 o$, spinal trigeminal nucleus oralis; $v c$, ventral cochlear nucleus; 7 , facial nucleus. Scale bar, $1.7 \mathrm{~mm}$.

To begin to examine the degree to which RGSs in brain might be similarly regulated, we used the ECS paradigm. Acute ECS induces dramatic regulation of numerous brain mRNAs and proteins in discrete brain regions and has been used as a model of activity-dependent changes in gene expression (see Hope et al., 1994; Nibuya et al., 1996). We focused on one of the most profoundly affected brain regions, the dentate gyrus granule cell layer ( $\mathrm{gcl}$ ), where RGS10 is by far the most abundant subtype mRNA (see Fig. 4). In addition, the gcl is a remarkably homogenous neuronal population. Given the cellular homogeneity and the predominance of RGS10 mRNA, changes in RGS10 levels could have profound effects on G-protein signaling in these neurons. As can be seen in Figure 13, a single ECS induced timedependent decreases in RGS10 mRNA in both the gcl and superficial pyramidal layers of parietal neocortex. In gcl, decreases were apparent by $8 \mathrm{hr}$ after ECS and maximal at $24 \mathrm{hr}$, falling to almost $60 \%$ of control levels, but had largely returned to normal by $7 \mathrm{~d}$ after ECS. Changes in neocortex followed a similar time course but were more modest. In addition to RGS10, the response to acute ECS of RGS7 and RGS8 mRNA, two transcripts present in the gcl at more modest concentrations, were also assessed. Changes in these transcripts were more transient, with significant changes occurring only $8 \mathrm{hr}$ after ECS [RGS7 increased by $36 \%$ ( $p<0.01$, Dunnett's multiple comparison test), and RGS8 decreased by $14 \%$ ( $p<0.01$, Dunnett's multiple comparison test)].

\section{DISCUSSION}

The major finding of the present study is the distinct regional specificity of the mRNAs for nine subtypes of RGS proteins, which had previously been shown by PCR or Northern blot analysis to be present in brain (Druey et al., 1996; Koelle and Horvitz, 1996). Some mRNAs are broadly distributed, whereas others are highly localized and relatively restricted to a small number of brain regions. The patterns of expression of the RGS mRNAs are consistent with neuronal localization, although there were indications that at least some of the RGS mRNAs were expressed in glia.

One of the most dramatic patterns of expression was observed for RGS9 mRNA, which was highly enriched in striatal regions, including caudoputamen, nucleus accumbens, and olfactory tubercle. In this respect, the pattern of expression of RGS9 mRNA resembles that for many other striatal-enriched proteins, including several subtypes of dopamine receptors (Meador-Woodruff, 1994), G $\alpha$ olf (Herve et al., 1993), adenylyl cyclase type V (Glatt and Snyder, 1993), and DARPP-32 and other striatal-enriched phosphoproteins (Hemmings et al., 1989; Brene et al., 1994). Given this localization for RGS9 mRNA, and the likelihood that this protein is at least somewhat specific for Gi- and Go-coupled receptors, one possibility is that RGS9 specifically modulates signaling via the $\mathrm{D}_{2}$-like dopamine receptors. Although RGS9 mRNA is highly enriched in striatal regions, it is not the only 


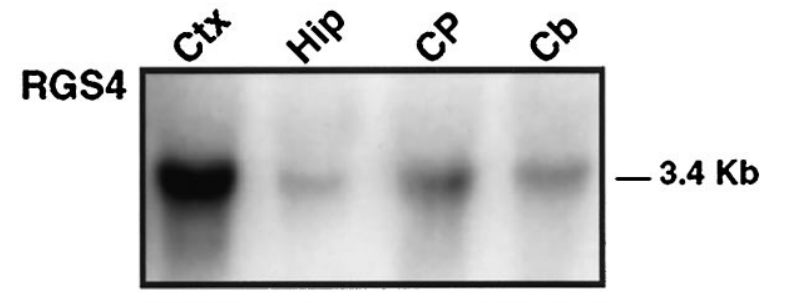

\section{RGS8}
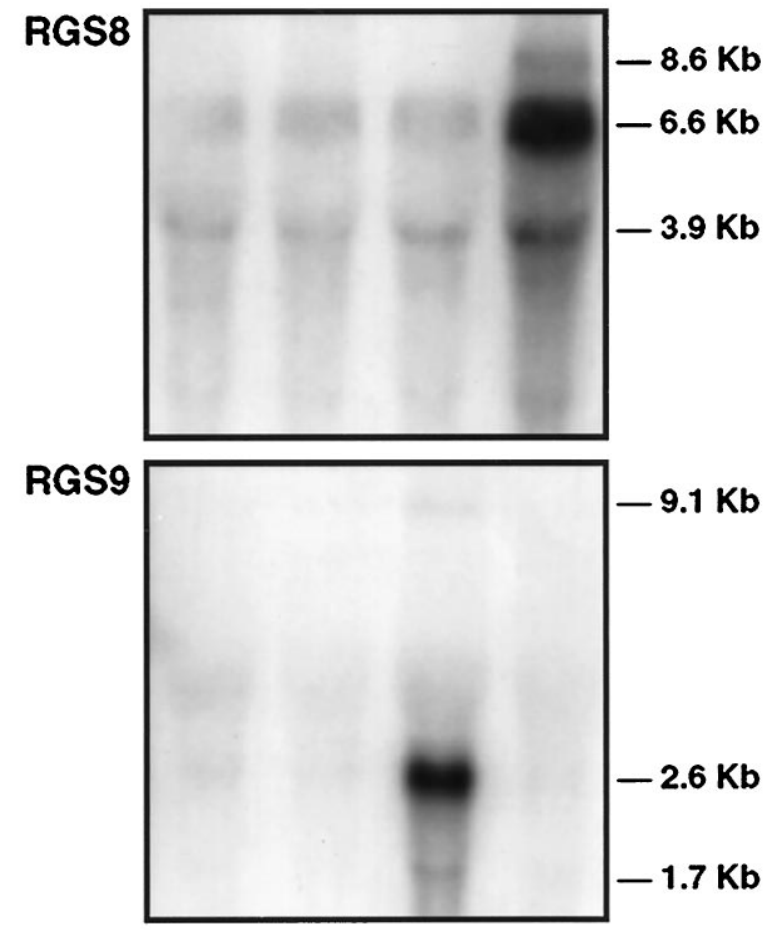

$-9.1 \mathrm{~Kb}$

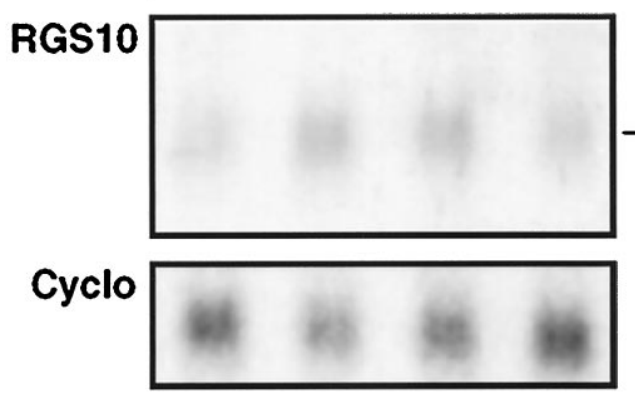

Figure 12. Northern Blot hybridization of ${ }^{32} \mathrm{P}$-labeled cRNAs for RGS4, RGS8, RGS9, RGS10, and cyclophilin (cyclo) to whole mRNA (10 $\mu \mathrm{g} /$ lane) from neocortex (Ctx), hippocampus (Hip), caudoputamen $(C P)$, and cerebellum $(\mathrm{Cb})$ of rat. All four RGS probes hybridize to clear principal bands, with hybridization most enriched in cortex, cerebellum, and caudoputamen for RGS4, RGS8, and RGS9, respectively. For RGS10, hybridization is similarly dense in both hippocampus and caudoputamen. The RGS8 and RGS9 cRNAs also hybridize to several minor bands. Kilobase markers indicate significant bands of hybridization for each RGS cRNA.

RGS subtype mRNA found at appreciable levels in these regions. This is analogous to some of the other striatal-enriched signaling proteins, for example, adenylyl cyclase type V and Goolf. Although these subtypes are enriched in striatum, several other forms of adenylyl cyclase and G-protein $\alpha$ subunits are expressed at high levels in these regions.

Patterns of expression of other RGS subtypes are also noteworthy. RGS4 mRNA is perhaps the most widely distributed and
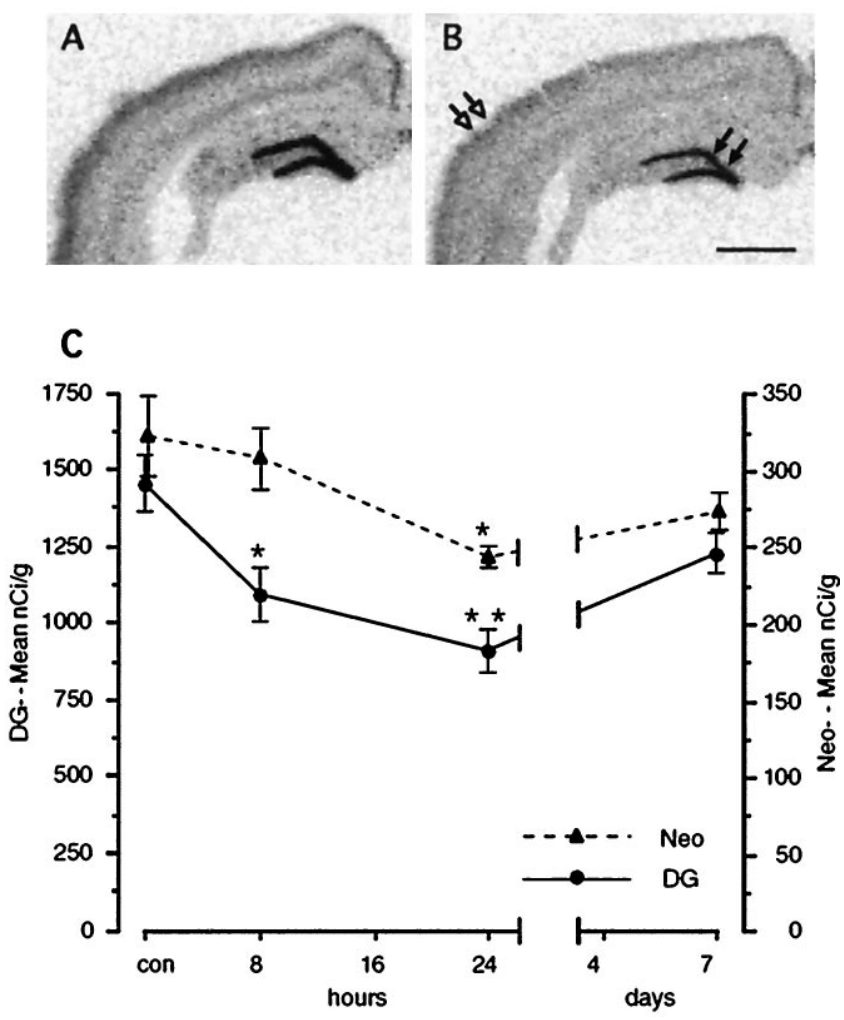

Figure 13. RGS10 mRNA is downregulated after acute ECS stimulation. At $24 \mathrm{hr}$ after acute ECS (B), RGS10 cRNA labeling is decreased in parietal neocortex (open arrows) and dentate gyrus granule cell layer (closed arrows) relative to control levels $(A)$. The time course of changes $(C)$ shows that a marked decrease occurs between 8 and $24 \mathrm{hr}$ after ECS, and that labeling densities have returned close to control levels by $7 \mathrm{~d}$ after ECS. ${ }^{*} p<0.05 ;{ }^{*} p<0.01$ (ANOVA, Dunnett's test). Scale bar, $1.5 \mathrm{~mm}$.

highly expressed RGS subtype mRNA in brain. It is present at high levels in cerebral cortex, striatum, and thalamus as well as in several brainstem nuclei. Within cortex, RGS4 mRNA shows a striking layer-specific distribution. RGS8 mRNA was interesting for its expression in several brainstem nuclei involved in basal ganglia function. For example, it was expressed at high levels in substantia nigra, ventral tegmental area, and lateral parafascicular and subthalamic nuclei. RGS10 mRNA was striking for its intense enrichment in the dentate gyrus granule cell layer, although it was also found in several other brain regions at lower yet substantial levels, including dorsal raphe and superficial layers of neocortex. RGS3 mRNA was largely restricted to thalamus, although it was not by any means the most abundant RGS mRNA in this brain region. It must be emphasized that all of these expression patterns are based on levels of mRNA for the various RGS proteins. A major focus of future research will be to define the patterns of expression of the proteins themselves. This will require the development of subtype-specific antibodies, which are not available now.

Given the proposed role of RGS proteins as GTPase-activating proteins for G-protein $\alpha$ subunits, one major question is: By what mechanisms are RGS proteins themselves regulated in the brain? In yeast, the best established mechanism of regulation is at the level of RGS expression (Dohlman and Thorner, 1997). A similar phenomenon has been observed in lymphocytes, in which several types of stimuli lead to enhanced expression of various RGS 
subtypes (Murphy and Norton, 1990; Hong et al., 1993; Siderovski et al., 1994). The physiological role served by this regulation remains unknown, because these observations were made before the functional activity of the RGS proteins was established. Nevertheless, increased levels of RGS proteins were shown to inhibit G-protein signaling in transfected cells (Druey et al., 1996; Neill et al., 1997). This was expected because increased RGS levels would lead to increased GTPase activity of the associated G-protein $\alpha$ subunits and thereby to decreases in the duration of the activated G-protein signal. Such regulation could exert profound effects on cell functioning.

As a first attempt to assess possible regulation of RGS proteins in brain, we examined RGS7, RGS8, and RGS10 mRNA levels in hippocampus after an acute ECS. We chose these three subtypes, because they are highly expressed in hippocampus, which is known to undergo intense epileptiform activity during this treatment. We found that levels of RGS10 mRNA were reduced by almost half in the dentate gyrus, with maximal effects observed between 8 and $24 \mathrm{hr}$ after the ECS. Levels recovered within $7 \mathrm{~d}$. Similar, albeit less robust, regulation of RGS10 mRNA was observed in superficial layers of neocortex. A corresponding decrease in RGS10 protein levels would be expected to result in the facilitation of Gi- and Go-mediated receptor signaling, which could, in turn, represent an adaptive response to the intense synaptic stimulation by ECS of a host of neurotransmitters known to act through $\mathrm{Gi}$ and Go in hippocampus (e.g., norepinephrine, serotonin, and several neuropeptides). The observed decrease in RGS10 expression is particularly noteworthy, because it is the first demonstration that levels of an RGS protein can be downregulated. The responses of RGS7 and RGS8 mRNA levels to ECS were more transient, with a significant increase in RGS7 and a small decrease in RGS8 seen $8 \mathrm{hr}$ after treatment.

Although these findings are clearly just the initial characterization of the regulation of RGS proteins in brain, they do nevertheless raise the interesting possibility that regulation of RGS proteins may be widespread and may contribute in important ways to adaptive responses in brain signal transduction pathways. If this proves true, then RGS proteins could provide novel mechanisms for desensitization and sensitization of G-protein-coupled receptor function. These studies also highlight the unique power of model organisms, such as $S$. cerevisiae and Caenorhabditis elegans, in revealing new families of proteins, the homologs of which subserve essential signaling functions in mammalian brain.

Results of the present study provide fundamental information concerning the localization of a newly discovered class of signaling protein in the brain. The highly region-specific patterns of RGS mRNA expression suggest that certain subtypes may be associated with specific types of receptors or other signaling proteins by virtue of their coexpression in the same tissue. In addition, it will be important in future investigations to determine whether the various RGS proteins also exhibit distinct regulatory and functional properties and whether they show distinct subcellular localizations. This information promises to expand our knowledge of the vast repertoire of molecular mechanisms governing the intensity and cell type specificity of signaling in the nervous system. In addition, because the expression of RGS proteins is, in many cases, considerably more restricted than that of most G-proteins or G-protein-coupled receptors, RGS proteins represent novel and potentially exciting targets for the development of new psychotropic medications.

\section{REFERENCES}

Alvaro JD, Tatro JB, Quillan JM, Fogliano M, Eisenhard M, Lerner MR, Nestler EJ, Duman RS (1996) Morphine down-regulates melanocortin-4 receptor expression in brain regions that mediate opiate addiction. Mol Pharmacol 50:583-591.

Berman DM, Wilkie TM, Gilman AG (1996a) GAIP and RGS4 are GTPase-activating proteins for the Gi subfamily of $G$ protein alpha subunits. Cell 86:445-452.

Berman DM, Kozasa T, Gilman AG (1996b) The GTPase-activating protein RGS4 stabilizes the transition state for nucleotide hydrolysis. J Biol Chem 271:27209-27212.

Brene S, Lindefors N, Ehrlich M, Taubes T, Horiuchi A, Kopp J, Hall H, Sedvall G, Greengard P, Persson H (1994) Expression of mRNAs encoding ARPP-16/19, ARPP-21, and DARPP-32 in human brain tissue. J Neurosci 14:985-998.

Bruch RC, Medler KF (1996) A regulator of $G$ protein signaling in olfactory receptor neurons. NeuroReport 7:2941-2944.

Chan RK, Otte CA (1982) Isolation and genetic analysis of Saccharomyces cerevisiae mutants supersensitive to $\mathrm{G} 1$ arrest by a factor and alpha factor pheromones. Mol Cell Biol 2:11-20.

Chen CK, Wieland T, Simon MI (1996) RGS-r, a retinal specific RGS protein, binds an intermediate conformation of transducin and enhances recycling. Proc Natl Acad Sci USA 93:12885-12889.

Chen C, Zheng B, Han J, Lin S-C (1997) Characterization of a novel mammalian RGS protein that binds to $\mathrm{G} \alpha$ proteins and inhibits pheromone signaling in yeast. J Biol Chem 272:8679-8685.

De Vries L, Mousli M, Wurmser A, Farquhar, MG (1995) GAIP, a protein that specifically interacts with the trimeric $\mathrm{G}$ protein $\mathrm{G} \alpha_{\mathrm{i} 3}$ is a member of a protein family with a highly conserved core domain. Proc Natl Acad Sci USA 92:11916-11920.

Dohlman HG, Thorner J (1997) RGS proteins and signaling by heterotrimeric G proteins. J Biol Chem 272:3871-3874.

Dohlman HG, Apaniesk D, Chen Y, Song J, Nusskern D (1995) Inhibition of G-protein signaling by dominant gain-of-function mutations in Sst2p, a pheromone desensitization factor in Saccharomyces cerevisiae. Mol Cell Biol 15:3635-3643.

Druey KM, Blumer KJ, Kang VH, Kehrl JH (1996) Inhibition of Gprotein-mediated MAP kinase activation by a new mammalian gene family. Nature 379:742-746.

Faurobert E, Hurley JB (1997) The core domain of a new retina specific RGS protein stimulates the GTPase activity of transducin in vitro. Proc Natl Acad Sci USA 94:2945-2950.

Gall C, Lauterborn J, Guthrie K (1995) In situ hybridization: a sensitive measure of activity-dependent changes in neuronal gene expression. In: Autoradiography and correlative imaging (Stumpf WE, Solomon HF, eds), pp 379-399. San Diego: Academic.

Glatt CF, Snyder SH (1993) Cloning and expression of an adenylyl cyclase localized to the corpus striatum. Nature 361:536-538.

Hemmings Jr HC, Nairn AC, McGuinness TL, Huganir RL, Greengard P (1989) Role of protein phosphorylation in neuronal signal transduction. FASEB J 3:1583-1592.

Hepler JR, Berman DM, Gilman AG, Kozasa T (1997) RGS4 and GAIP are GTPase-activating proteins for Gq alpha and block activation of phospholipase $\mathrm{C}$ beta by gamma-thio-GTP-Gq alpha. Proc Natl Acad Sci USA 94:428-432.

Herve D, Levi-Strauss M, Marey-Semper I, Verney C, Tassin JP, Glowinski J, Girault JA (1993) G(olf) and Gs in rat basal ganglia: possible involvement of G(olf) in the coupling of dopamine D1 receptor with adenylyl cyclase. J Neurosci 13:2237-2248.

Hong JX, Wilson GL, Fox CH, Kehrl JH (1993) Isolation and characterization of a novel B cell activation gene. J Immunol 150:38953904.

Hope BT, Kelz MB, Duman RS, Nestler EJ (1994) Chronic electroconvulsive seizure (ECS) treatment results in expression of a long-lasting AP-1 complex in brain with altered composition and characteristics. J Neurosci 14:4318-4328.

Hunt TW, Fields TA, Casey PJ, Peralta EG (1996) RGS10 is a selective activator of G $\alpha$ i GTPase activity. Nature 383:175-177.

Koelle MR (1997) A new family of G-protein regulators-the RGS proteins. Curr Opin Cell Biol 9:143-147.

Koelle MR, Horvitz HR (1996) EGL-10 regulates G protein signaling in the $C$. elegans nervous system and shares a conserved domain with many mammalian proteins. Cell 84:115-125.

Meador-Woodruff JH (1994) Update on dopamine receptors. Ann Clin Psychiatry 6:79-90. 
Murphy JJ, Norton JD (1990) Cell-type specific early response gene expression during plasmacytoid differentiation of human $\beta$-lymphocyte leukemia cells. Biochim Biophys Acta 1049:261-271.

Neer EJ (1995) Heterotrimeric G proteins: organizers of transmembrane signals. Cell 80:249-257.

Neer EJ (1997) Intracellular signalling: turning down G-protein signals. Curr Biol 7:R31-R33.

Neill JD, Duck LW, Sellers JC, Musgrove LC, Scheschonka A, Druey KM, Kehrl JH (1997) Potential role for a regulator of $G$ protein signaling (RGS3) in gonadotropin-releasing hormone $(\mathrm{GnRH})$ stimulated desensitization. Endocrinology 138:843-846.

Nibuya M, Nestler EJ, Duman RS (1996) Chronic antidepressant administration increases the expression of CREB in rat hippocampus. J Neurosci 16:2365-2372.

Paxinos G, Watson C (1986) The rat brain in stereotaxic coordinates. San Diego: Academic.
Siderovski DP, Heximer SP, Forsdyke DR (1994) A human gene encoding a putative basic helix-loop-helix phosphoprotein whose mRNA increases rapidly in cycloheximide-treated blood mononuclear cells. DNA Cell Biol 13:125-147.

Watson N, Linder ME, Druey KM, Kehrl MH, Blumer KJ (1996) RGS family members: GTPase-activating proteins for heterotrimeric Gprotein $\alpha$-subunits. Nature 383:172-175.

Wieland T, Chen CK, Simon MI (1997) The retinal specific protein RGS-r competes with the gamma subunit of cGMP phosphodiesterase for the alpha subunit of transducin and facilitates signal termination. J Biol Chem 272:8853-8856.

Winston SM, Hayward MD, Nestler EJ, Duman RS (1990) Chronic electroconvulsive seizures down-regulate expression of the immediateearly genes c-fos and c-jun in rat cerebral cortex. J Neurochem 54:19201925. 